\title{
Decision-making in product portfolios of pharmaceutical research and development - managing streams of innovation in highly regulated markets
}

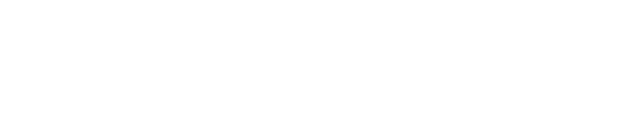

\author{
Antti Jekunen \\ Vaasa Oncology Clinic, \\ Vaasa, Finland
}

Correspondence: Antti Jekunen

Vaasa Oncology Clinic, Hietalahdenkatu 2-6, Vaasa, Finland

Email antti.jekunen@vshp.fi

\begin{abstract}
Decision-making is a core function of any drug development firm. Developing drugs demands a firm to be highly innovative, while at the same time the activity is strictly regulated. Successful drug development offers the right to apply for a long-term patent that confers exclusive marketing rights. This article addresses the issue of what constitutes an adequate portfolio of drugs for a drug development firm and how it might be managed successfully. The paper investigates decision-making in the industry and specifically in the development of oncology drugs from various perspectives: the need for decisions, their timing, decision-making at the project level, the optimal portfolio, tools for portfolio analysis, the evaluation of patents, and finally the importance of the drug portfolio. Drug development decisions as important organizational elements should get more emphasis, and decisions in drug portfolio using modern decision-making methods should be used more widely than what currently happens. Structured, informed decisions would help avoiding late terminations of drugs in Phase III development. An improved research and development pipeline and drug portfolio management are the major elements in the general strategy targeting success.
\end{abstract}

Keywords: decision-making, drug development, clinical oncology, product management, pipeline, portfolio, portfolio analysis, company organization

\section{Introduction}

One of the core functions in all companies is to make valid decisions efficiently and in a timely manner. Drug development is particularly tightly connected with timing, as financial obligations follow closely from the different phases of drug development, each of which has a specific need for financing. Phase III clinical development is particularly expensive, and there have been apparently strong candidate drugs that have failed in Phase III and never made it to market. Of course, it would be in the interests of the developing company to be able to discontinue development of an agent that is destined to fail to be approved as early as possible, and thus minimize financial losses.

Decisions should be made in a coordinated sequence, taking into account of the financial aspects of the development plan for an individual drug. Decision-making should be viewed as a dynamic process that changes over time, rather than one that remains static, even within the same organization. ${ }^{1}$ Company size determines how much of the preparatory work for decision-making can be done in-house and how much needs to be outsourced. Decision-making itself is difficult to delegate outside the company, at least where it concerns important company-wide issues. In certain 
situations, for instance, where the matter to be addressed relates more to a project than to the construction of a portfolio, decision-making is simpler and may be outsourced when it addresses a restricted set of questions. However, despite the importance of making optimal decisions while managing drug pipelines, human judgment rather than any formal analytical method is used in pharmaceutical companies. ${ }^{2}$ In this study, the various aspects of commercial decision-making and specifically that concerning the development of drugs in oncology will be investigated; these aspects include: the need for decisions, their timing, decision-making at the project level, the optimal portfolio, tools for portfolio analysis, the evaluation of patents, and finally, the importance of the drug portfolio (Figure 1).

\section{Pipeline and portfolio}

A drug development company typically has many projects, and a leading drug molecule and several other molecules that form a pipeline. In a drug development pipeline, new products in different phases of development form repeating sequences of similar projects. Projects are separate and attuned to each individual drug, but the projects encompass very similar activities that have to be repeated. The pipeline produces a drug portfolio, which can include both approved drugs and candidate drugs. Therefore, the drug development portfolio might equate to the pipeline when all drugs are under development.

\section{The need for decisions}

Decision-making is a core function of any firm. Without making decisions, it is simply not possible to stay in business. Generally, product development can be organized into two categories: the decisions made within a single developmental project and those decisions a firm makes in establishing an organizational context and in planning its projects. ${ }^{3,4}$ While many people make decisions on single projects, there are only a few people within a firm able to make organizational decisions spanning several projects (Figure 1). That small group must have access to sufficient information about the science, manufacturing issues, marketing, and financial aspects of the project to base its decisions upon. Specific success factors include the firm's internal clinical capabilities, the ability to internalize critical external knowledge as well as the means by which the firm organizes developmental activities with key partners. ${ }^{5}$ Further success factors relating to research and development (R\&D) have been cited, including: selecting prime targets for drug discovery, driving rapid experiments that provide decision-critical information, focusing limited

\section{\begin{tabular}{|l|}
\hline Need for decisions \\
\hline Need for experts \\
\hline
\end{tabular}}

Timing for decisions

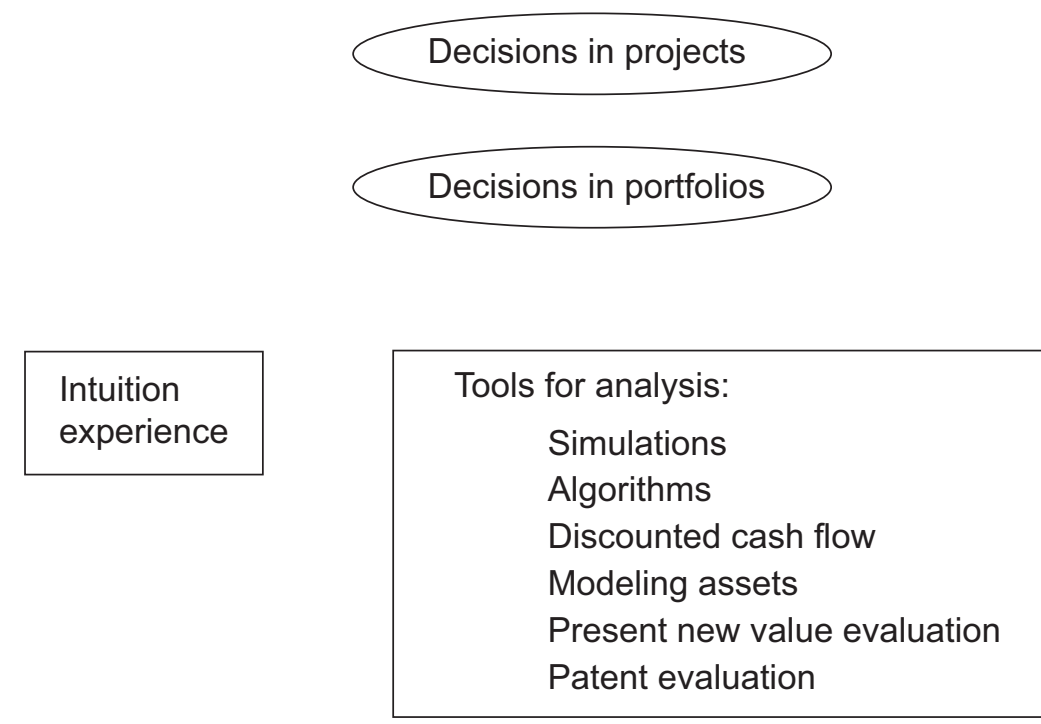

Figure I Decision-making in drug development.

Notes: There is a need for decisions that requires experts and preplanned decision time points. While each project will need decisions in a timely manner upon project progression, a portfolio needs constant decision-making at preplanned time points to ensure that the portfolio will match to the business plan of the company. 
resources to enhance speed, breaking down barriers between research and manufacturing, and managing product life cycles effectively. ${ }^{6}$ If there is a need for international $R \& D$, the extra costs must be balanced by synergy effects such as reduced time-to-market, improved effectiveness, and enhanced learning capabilities. ${ }^{5}$ Currently, consultants are used more and more, and in some cases, excessively. As a rule, a firm will consider using a consultant in an area that is important but that does not need continuous actions. A permanent member of staff should be considered, if work tasks are repeatedly needed. The firm's characteristics and way of conducting development has implications for decision-making. Clearly, different organizations will make different choices and may use different methods, but each makes decisions on a collection of issues, such as product concept, architecture, configuration, procurement, distribution arrangements, and project schedule. ${ }^{3}$

Ultimately, the board of directors is responsible for decisions that define a drug portfolio, but whether it has the appropriate expertise to apply rational thinking to development issues depends on how it is constituted. In a small firm, the board of directors can substitute lack of expertise in operational site; thus, financial skills and knowledge about actual operational aspects are helpful. On the other hand, when the firm size increases together with the level of expertise, a need of focused specialists in the board of directors decreases, and other characteristics become more important, such as good social network, political connections, and visions about the future (Table 1). Of course, skills in firm self-regulation and media skills would be helpful as there is a tendency of getting bad publicity when firm size has reached a certain level. Nowadays, pharmaceutical firms are increasingly relying on academic partnerships for their drug discovery research. This is a new model where firms are reducing their burden of investments in discovery research and collaborating more closely with academic institutions. By using collaboration contracts that prioritize the firm to get developed innovation first before competitors, it is possible to avoid expensive

Table I Optimal representation of main special areas in the board of directors

\begin{tabular}{llll}
\hline Characteristics & Small firm & Middle firm & Big firm \\
\hline Finance & +++ & +++ & +++ \\
Drug development & ++ & +++ & + \\
Marketing & & + & +++ \\
Social aspects & & ++ & +++ \\
Future innovation & + & ++ & +++ \\
\hline
\end{tabular}

Note:,,++++++ grading refers to the importance of having a functional characteristic inside a board of directors.

Abbreviations: +, useful to have; ++, helping a lot; +++ critical. competitive auctions. In addition, a small biotechnology company can collaborate with a big pharmaceutical company and use more specialists than otherwise possible. This can be seen in collaborations between early development firms with a promising drug candidate, which is then sold conditionally to the bigger company for further development in later clinical phases. Strategy needs to be developed and executed to create and maintain a lively drug development environment and a team capable of swift responses. ${ }^{7}$ In every case, issues and decision requests need to be prepared by operational people or consultants if knowledge is not inside the firm. Today, many large- and middle-size pharmaceutical firms have elaborated their drug development organizations after proof of concept stage toward cross-functionality by including clinicians, pharmacologists, statisticians, and persons for regulatory and project management. The cross-functional nature of these teams enables the decision-making process to become comprehensive and circumspect. In general, these are aligned by disease area, with each disease area-responsible director empowered to make go/no-go decisions. Optimizing the structure and development pathway of biopharmaceutical drug portfolios includes making strategic decisions on the choice of drugs, the scheduling of critical activities, and the possible involvement of third parties in developmental activities and manufacturing at the various stages for each drug. ${ }^{8}$ The main brake on the process will be restricted cash flow that will reduce the likelihood of success. George and Farid suggest that naively applying strategies optimal for a particular size of portfolio to a portfolio of another size is inappropriate. ${ }^{8}$ In a pharmaceutical firm, there is an obligation to make decisions all the time in the course of drug development, and principally, it is the quality of those decisions that will determine the fate of the organization. Good decisions will drive activity, but bad ones will reduce the effectiveness of processes. Decisions should be in accordance with the business plan and in harmony with the firm's mission. Today's pharmaceutical firms form the nodes in large-scale scientific networks that include biotech companies and also universities. ${ }^{9}$ Consequently, decision-making has become more complex than in the past and now involves many companies and so demands intense cooperation.

\section{Timing of decisions}

In project management, it is necessary to obtain decisions at certain points along a development process. ${ }^{5}$ In small biotechnology companies, regulatory and capital requirements, as well as investors' expectations, are important functions throughout clinical phase trials. ${ }^{2}$ There are normally many 
decisions to be made when the development processes get underway. Decision-making at the early discovery level would involve in-licensing activities depending on whether the molecule fits to the planned target drug profile. Critical decisions in early drug development such as candidate selection, early proof of concept/principle, dose ranging, development risks, and patient stratification can substantially shorten clinical development time, while the selection and evaluation of biomarkers are based on the appropriate measurements of biomarkers that are biologically and/or clinically validated. ${ }^{10}$ Before undertaking a development project, the organization should ensure that it has planned thoroughly and that it has adequate resources in place. All these issues are addressed in a proper drug development plan. Drug target and candidate selection are two of the key decision points within the drug discovery process, and all firms use certain selection criteria for decisions on which targets to accept into their discovery pipelines and which compounds will proceed to the development stage. ${ }^{11}$ Preclinical data gathering must be completed before human trials. Animal studies covering toxicity and interactions are particularly important, because safety issues that can be tracked back to preclinical data are a common reason for terminating trials at a later stage. Initiation of a new drug development process is a big decision and data on a drug molecule has to be ready so that an evaluation on the likelihood of development can proceed. A decision will definitely be required when the intensity or timeline of a project changes. Such changes may be necessitated by the development itself facing problems, or because a competitor has got a rival drug to market, or by a shift in the financial climate. Some of these points can be defined beforehand, which makes development more dynamic and increases the level of control. Of course, new goals and more aggressive timelines need to be dealt with separately, and decisions must be based on adequate information in updated drug development plans.

The most important, and at the same time the most difficult, decision is dealing with project termination. This decision needs to be made early and rapidly. The rules governing it should be formulated even as the project is initiated. The best practice is to schedule evaluation points along the project timeline focusing on the positives and negatives of continuing. If development is terminated based only on a panic reaction to poor study results, that decision has been made far too late. By that point, too much time and money have been wasted, which calls into question not only the decision process but can even jeopardize the very existence of the company. ${ }^{12}$ In drug development, all decisions,
Table 2 Timing of decision points

Initiation of proof of concept
Preclinical
Phase 0
Phase I
Phase II
Phase III
Line-extension phase

including a termination decision, need to be planned. The timing of decisions should be predetermined based on the availability of new data and financial considerations. Spontaneous termination might well be unavoidable on occasion, but it is infinitely preferable if such a decision is triggered by predetermined events. Such events might include the discovery of unwelcome side effects, marginal efficacy, competition in-house, or competing candidates (Table 2). ${ }^{13}$ It is very important that senior management decide to either continue a project or to immediately terminate it. ${ }^{14}$ That decision will often be justified by reference to economic and/or financial issues. ${ }^{15}$

\section{Decision-making at the project level}

Every research project can be evaluated separately using an analysis technique such as the goal contribution, the decision tree, utility usage, and risk analysis, ${ }^{16}$ or alternatively, simulations might be used. Projects are mainly structured around separate drug candidates and proceed from preclinical through clinical stages. In oncology, the clinical phase includes Phase I-III trials, which may be preceded by a clinical proof of concept with micro-doses as Phase 0 (see Table 3). ${ }^{17}$ While determining the optimal point at which to cease Phase II trials is best achieved by evaluating the tradeoff between benefit and cost, and adopting new objectives for the decision-making process, which rarely happens in practice. ${ }^{18}$ Chen et al ${ }^{18}$ provide optimal design strategies for proof of concept trials that include optimal go/no-go decision criteria for the initiation of Phase III and optimal resource allocation strategies for conducting multiple trials

Table 3 Reasons for termination

Disappointments in a product (unwanted side effects or marginal
efficacy)
Change in product environment (internal and external competition)
Change in financing
Preplanned evaluations for terminations:
After Phase 0
After Phase I-II
Before Phase III


on a portfolio with constrained resources. Quality needs to be constantly built during the whole clinical development from early clinical studies through to the data catering Phase II stage in order to make prudent and prescient decisions at Phase III stage. Along the way, clinical studies of good design are heavily needed. Regulatory and capital requirements, and investors' expectations, all shape a firm's product development projects and are important factors in all trials at every phase. ${ }^{19}$ In the projects, prior experience and a similar background are important to the development, and having a unified platform available for several compounds would make development significantly easier. R\&D has many repeating practical decision points relating to projects. These predefined points are essential requirements for projects in order that they move forward. ${ }^{20}$ In addition, there are decisions to be made on the licensing of new compounds and licensing-out existing compounds, and on whether to continue ongoing projects or terminate them. One important issue to cover is whether the candidate will fit to the target drug profile and finally to the target drug portfolio. Companies are continuously seeking ways to reduce uncertainties, shorten development lead times, and cut costs. ${ }^{21}$ The importance of having a senior management group capable of making these decisions is well-recognized. Product platforms are planned to repeat functions on related compounds to accrue benefits in efficacy and costs. They are component and subsystem assets shared across a product family that help a firm improve its leverage of investments in product design and development; however, that approach may involve a greater investment of time and money. Nevertheless, it may pay dividends later as the integration benefits from platforms increase and the overdesign costs of platforms decrease..$^{22}$

\section{The optimal portfolio}

Good drug products may form a complete and realistic portfolio that is aligned with the developing firm's business plan and its strategy. ${ }^{23}$ However, a development portfolio should have a schedule and timescale. The development of the agent that has the most potential to be successful should be prioritized, and should be followed by the agent with the next best potential for success, and so on. Filling the portfolio is actually a dynamic process that produces upfront movements by pushing drug candidates forward, and at certain time points, repeatedly evaluates the very basis of the process. ${ }^{15}$ In oncology, it is well-recognized that something like every fifth drug entering clinical development will actually eventually be approved. The statistic indicates that a drug development firm would be best served by having five drug candidates in the pipeline. The high attrition rate necessitates considering financial limitations early on and throughout the whole development period. The best case for the drug developer is to have numerous options at the early stages that are reduced by the strict selection of preclinical agents to ensure that only the most promising compounds reach the clinical phase. ${ }^{24}$ Having a schedule and order of agents is extremely important. There should be backup agents available in case it proves necessary to cease development of the lead compound. In all other cases, risk evaluation should start immediately, and only after thorough analysis should development decisions be made.

However, all development projects face some difficulties, which do not necessarily stop projects but can slow them down considerably. A suitable point to rest backup agents occurs when the clinical phase is about to start, at the end of Phase II (Table 3). At certain points, the whole development plan should be reviewed and only if all critical elements are positive and accord with the planned drug characteristics should development continue. It is generally accepted that the optimal portfolio does not contain too many agents, but is supported by realistic timelines, a clear prioritization of development activities, and adequate financial support. ${ }^{25}$ A mathematical framework with a value-driven approach to optimizing pharmaceutical portfolios should be used to determine optimum sample sizes and trial schedules to maximize the value of a portfolio under budgetary constraints. ${ }^{26}$ The same model can be used to answer a variety of "what if" questions that reflect situations that arise in practice. This is extremely important, not least because financial issues pose one of the biggest challenges to drug development.

\section{Tools for portfolio analysis}

There are several methods that can be used as evaluation tools in product pipeline assessment. ${ }^{27}$ At the pipeline level, it is important to prioritize available projects and fund the best (Figure 1). A large number of pharmaceutical companies organize their projects by using a similar set of criteria: typical examples include consideration of the commercial value of a potential drug; the risk of pursuing an alternative approach to identification; the competitive situation of the firm; and in some arenas, also the novelty of the drug or the therapy. ${ }^{28}$ The ideal structure of the product pipeline is driven by the cost of development of the drugs, the likelihood of them surviving the approval process, and finally the expected profitability. ${ }^{16}$ One challenge is to choose the right number of approaches as well as individual compounds to be funded at each stage. 
At the point where products are approved, what was a pipeline becomes a product portfolio. Portfolios can be evaluated based on optimizing an objective function under a given set of constraints. ${ }^{29}$ The most common method informing the decision on whether to begin either preclinical research or full-scale development is the use of human judgment and prior experience rather than any formal analytical method. ${ }^{3}$ Intuition plays an important part in decision-making. However, more formal methods of analyzing drug pipeline portfolios are essential to make more informed decisions for balancing risks and maximizing returns. Decision analyses, simulations, and algorithms can all be used in the assessment of the risk and potential returns in R\&D portfolios to support decision-making. ${ }^{15}$

A financial perspective is commonly applied to decisionmaking on R\&D projects. ${ }^{30}$ The high level of risk and uncertainty associated with such projects makes it difficult to conduct complete portfolio level determinations based on financial aspects alone. One widely used financial tool using capital budgeting is the discounted cash flow technique (DCF). It is based on assessing the opportunity cost of capital by estimating future cash flow. Several other methods are also used, such as decision analyses, simulations, and the construction of algorithms. Moreover, what has been termed pharmacoeconomics has increasingly been used to augment capital budget decisions in pharmaceutical R\&D. It is evident that there is a great need to assess risk and returns relating to R\&D portfolios to aid executive strategic decision-making. Portfolio management can be carried out with a computationally intensive approach, which is suited to managing the complexity brought by the candidates' dependencies, pipeline resources, and economic and technical uncertainties; each of which must be managed before a sequence of new product development projects maximizing the expected economic returns at an acceptable level of risk for a given level of resources can be determined. ${ }^{15}$

While models of financial options rely on assets that have a known, tradable price, technology options have proved difficult to assign a specific dollar value to. Technology assets are less liquid and more difficult to identify than financial assets. In principle, technology is knowledge; developing new technology is acquiring new knowledge, and knowledge cannot be precisely quantified. ${ }^{31}$ The options approach to project valuation seeks to correct the deficiencies of traditional methods of valuation - net present value (NPV) and DCF - by promoting the recognition that active management and managerial flexibility can bring significant value to a project. ${ }^{31}$ Real option models are bringing the recognition of managerial flexibility to the forefront of NPV valuation models. Real options may belong to one of several categories: growth, expansion scale, timing, switch processes, contract scale, and abandonment.

\section{Evaluation of patents}

Patents are output measurements demonstrating technological capabilities. ${ }^{32} \mathrm{R} \& \mathrm{D}$ spending and patent counts are used in assessments, but both measurements are problematic. Several other more sophisticated methods are in use because of the inherent challenges involved in assessing the quality of patents. One such method is to explore how often others are referring to a certain patent. Other assessment tools include the evaluation of how revolutionary the product is, how it is visualized, its functionality, and its commercial potential. An accurate assessment requires the evaluation of current and future competition and knowledge of the options for substitution.

\section{Development stage of the company}

A primary objective for small firms (which are usually also young) is to raise the funds required for existing projects and for the R\&D function to further expand projects in the pipeline. ${ }^{3}$ Naturally, small drug discovery firms are focused on their drug candidates in their still developing pipelines, as they initially lack marketable products. There are numerous funding options, like venture capitalism, or forming a strategic alliance with a larger pharmaceutical corporation. Small firms generally only have one project or a platform upon which the growth of the firm is dependent, and in those cases, there is not yet a realistic R\&D portfolio to manage. Instead, there is a need to manage very limited resources directed at the critical aspects on the development of a lead project of a platform technology. ${ }^{33}$ It appears that only large organizations have real portfolios with numerous projects at various stages of development.

The longer the company's products have been on the market, the lower the annual capital investments made back into the company tend to be. After the first approval, the drug will usually be developed to expand the market impact. This is done by exploring new indications and developing a compound's characteristics; for example, potential combination uses with other drugs. Furthermore, line extensions are useful for extending development beyond the point when patent protection expires. This reflects on capital investments, where older compounds may not receive much investment, but new compounds and innovations are heavily invested in. Therefore, the number of patents may describe the condition 


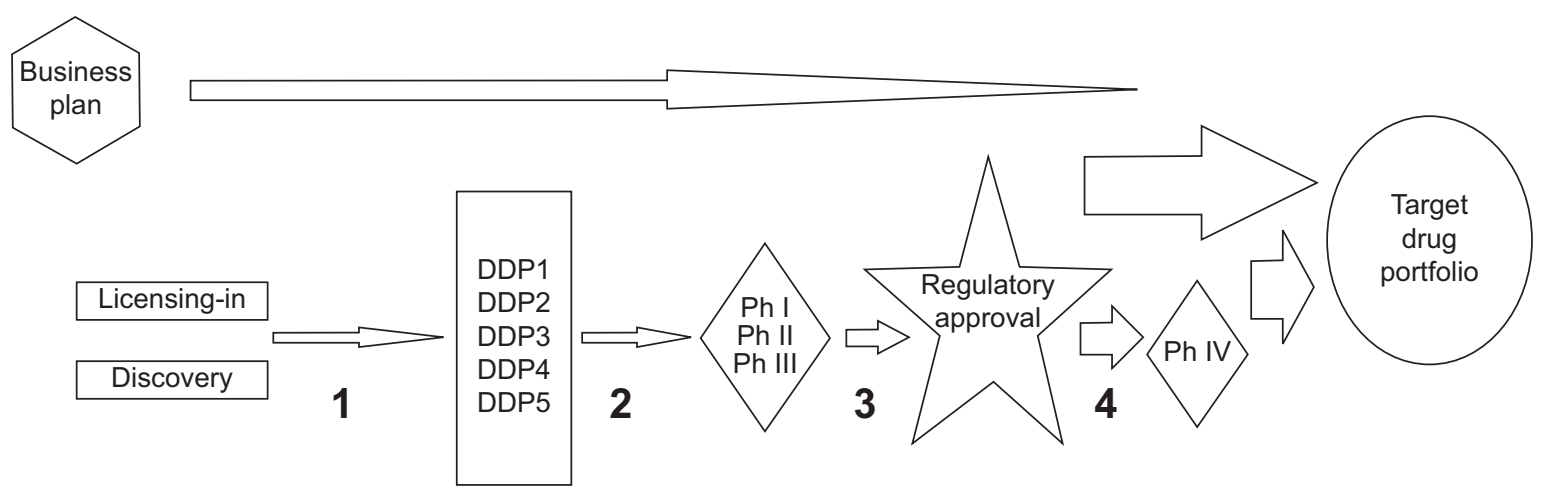

Figure 2 Recommendation for portfolio management.

Notes: Discovery and licensing-in activity will define DDPs for each drug candidate, which are then executed in clinical studies with the purpose of getting regulatory approval. Decisions need to be placed before selecting DDPs for clinical development and at a point when moving from preclinical to clinical and from Phase II to full-scale Phase III. As many DDPs will fulfill their target drug portfolio requirements, a drug portfolio will be filled for good drugs that are in harmony with the company's business plan. Recommended preplanned decision points are marked as numbers I-4.

Abbreviations: DDP, drug development plan; $\mathrm{Ph}$, phase.

of the pipeline for new compounds more accurately than it would the condition of pipelines for old compounds.

Normal pharmaceutical performance indicators, like sales, profits, and customer base are irrelevant to most small drug development companies with as yet no product on the market. However, the nature of an expected drug, ie, whether it is first in its class of mechanism of action and its probable market size and evaluated marketing performance, are among the most important factors to convince investors to continue financing in investigational development projects. In older companies with products already on the market, R\&D spending on the product pipelines could be expected to be reflected in higher sales..$^{32}$ In addition, performance of drug portfolios in the marketplace can give strict limitations to development, and even when a firm is succeeding and profit is steadily increasing, decreased investing in product pipelines may jeopardize the future. Improved R\&D pipeline management is one of the major elements in the general strategy targeting success. ${ }^{4}$

\section{Conclusion}

Corporate strategy determines the drug development pipeline with existing projects at different phases, and that then forms a firm's current drug portfolio. ${ }^{34}$ It is a procedure that demands effective decision-making. Decisions must be orchestrated according to a scheduled project plan integrated with the strategy of the company. Decision-making is an essential function of any company and determines long-term success. Recommendation is to form a portfolio plan, which consists from target drug profiles and how to get there in separate development plans for each agent. The entire development plan needs to be chalked out for Phase I to post-approval Phase IV studies, keeping in mind factors such as unmet medical need in the market, mechanism of action of the new agent, and activity in competitor space. Both the portfolio plan and each drug development plan need to be updated constantly, and decisions need to be made at preplanned decision points (Figure 2).

A pipeline matures into a drug portfolio requiring constant development and management. That portfolio can only become successful when supported by the right decisions. Decision-making is one of an organization's key functions and is at the core of determining how successful any single firm can be. Modern organizations often target collaboration, which makes organizational networks complex, but it also makes it feasible to build optimally structured functions with minimal cost.

\section{Acknowledgment}

This study was financially supported by the Competitive State Research Financing of the Expert Responsibility area of Tampere University Hospital, Grant number 1009.

\section{Disclosure}

The author reports no conflicts of interest in this work.

\section{References}

1. Garvin DA, Roberto M. What you don't know about making decisions. Harv Bus Rev. 2001;79(8):108-116.

2. Skrepnek GH, Sarnowski JJ. Decision-making associated with drug candidates in the biotechnology research and development (R\&D) pipeline. J Comm Biotech. 2007;13:99-110.

3. Krishnan V, Ulrich KT. Product development decisions: a review of the literature. Manage Sci. 2001;47(1):1-21.

4. Hultink EJ, Griffin A, Hart S, Robben HS. Industrial new product launch strategies and product development performance. J Prod Innovat Manag. 1997;14(4):243-257. 
5. Gassmann O, Reepmeyer G. Organizing pharmaceutical innovation: from science-based knowledge creator to drug-oriented knowledge brokers. Creativ Innov Manage. 2005;14(3):233-245.

6. Needleman P. From a twinkle in the eye to a blockbuster drug. Res Tech Manage. 2001;44(6):38-41.

7. Chan T, Nickerson JA, Owan H. Strategic management of R\&D pipelines with cospecialized investments and technology markets. Manage Sci. 2007;53(4):667-682.

8. George ED, Farid SS. Strategic biopharmaceutical portfolio development: an analysis of constraint-induced implications. Biotechnol Prog. 2008;24(3):698-713.

9. Albertini S, Butler J. R\&D networks in pharmaceutical company: some implications for human resource management. $R \& D$ Manage. 1995; 25(4):377-393.

10. Kuhlmann J. The applications of biomarkers in early clinical drug development to improve decision-making processes. Ernst Schering Res Found Workshop. 2007;(59):29-45.

11. Bakker A, Caricasole A, Gaviraghi G, et al. How to achieve confidence in drug discovery and development: managing risk (from a reductionist to a holistic approach). Chem Med Chem. 2009;4(6):923-933.

12. Raynor ME. The Strategy Paradox: Why Committing to Success Leads to Failure (and What to Do About It). New York: Random House Digital; 2007.

13. Adler PS, Mandelbaum A, Nguyen V, Schwere E. From project to process management: an empirically based framework for analyzing product development time. Manage Sci. 1995;41(3):458-484.

14. Lam MD. Knowing when to pull the plug on your experimental drug: how to succeed by failing faster. Pharmaceut Exec. 2004;3:55-60.

15. Blau GE, Pekny JF, Varma VA, Bunch PR. Managing a portfolio of interdependent new product candidates in the pharmaceutical industry. J Prod Innov Manage. 2004;21:227-245.

16. Ding M, Eliashberg J. Structuring the new product development pipeline. Manage Sci. 2002;48(3):343-363.

17. Jekunen AP, Pauwels EK, Kairemo KJ. Microdosing in early lead discovery. Bioanalysis. 2010;2(3):421-428.

18. Chen C, Sun L, Li CL. Evaluation of early efficacy endpoints for proofof-concept trials. J Biopharm Stat. 2013;23(2):413-424.

19. Bower JL, Gilbert CG. From Resource Allocation to Strategy. New York: Oxford University Press; 2005.
20. Cooper RG, Edgett SJ, Kleinschmidt EJ. Portfolio Management for New Products. 2nd ed. Cambridge, MA: Perseus Publishing; 2001.

21. Elmquist M, Segrestin B. Towards a new logic for front end management: from drug discovery to drug design in pharmaceutical R\&D. Creativ Innov Manage. 2007;16(2):106-120.

22. Krishnan V, Gupta S. Appropriateness and impact of platform-based product development. Manage Sci. 2001;47(1):52-68.

23. Sanwal A. Optimizing Corporate Portfolio Management: Aligning Investment Proposals with Organizational Strategy. Hoboken, NJ: John Wiley and Sons; 2007.

24. Murphy PL. Pharmaceutical project management - is it different? Project Manage J. 1989;3:35-38.

25. Graves SB, Rinquest JL, Case RH. Formulating optimal R\&D portfolios. Res Tech Manage. 2000;43(3):47-51.

26. Patel NR, Ankolekar S, Antonijevic Z, Rajicic N. A mathematical model for maximizing the value of phase 3 drug development portfolios incorporating budget constraints and risk. Stat Med. 2013;32(10): 1763-1777.

27. Girotra K, Terwiesch C, Ulrich KT. Valuing R\&D projects in a portfolio: evidence from the pharmaceutical industry. Manage Sci. 2007;53(9): $1452-1466$.

28. Hernàndez-Cuevas C. Collaborative innovation: the future of BioPharma. J Technol Manage Innov. 2007;2(3):1-3.

29. Rajapakse A, Titchener-Hooker NJ, Farid SS. Modelling of the biopharmaceutical drug development pathway and portfolio management. Comput Chem Eng. 2005;29:1357-1368.

30. Vuorinen I. Project evaluation methods for R\&D portfolio management. Tampereen yliopisto, Laskentatoimi, Seminaaritutkielma; 2005.

31. Jacob WF, Kwak YH. In search of innovative techniques to evaluate pharmaceutical R\&D projects. Technovation. 2003;23(4):291-296.

32. Renko M. Market orientation in markets for technology-evidence from biotechnology ventures. Turku School of Economics. 2006; Series A-8.

33. Tiggemann RF, Dworaczyk DA, Sabel H. Project portfolio management: a powerful strategic weapon in pharmaceutical drug development. Drug Inf J. 1998;32(3):813-824.

34. Rajegopal S, McGuin P, Waller J. Project Portfolio Management: Leading the Corporate Vision. New York: Palgrave Macmillan; 2007.
Drug Design, Development and Therapy

\section{Publish your work in this journal}

Drug Design, Development and Therapy is an international, peerreviewed open-access journal that spans the spectrum of drug design and development through to clinical applications. Clinical outcomes, patient safety, and programs for the development and effective, safe, and sustained use of medicines are a feature of the journal, which

\section{Dovepress}

has also been accepted for indexing on PubMed Central. The manuscript management system is completely online and includes a very quick and fair peer-review system, which is all easy to use. Visit http://www.dovepress.com/testimonials.php to read real quotes from published authors. 